\title{
Social dominance
}

\section{orientation and}

attitudes towards

climate-driven

migration

Presented by:

Samantha Stanley

Australian National University

13 February 2021

Coauthors:

Dr Caroline Ng Tseung-Wong, Dr Zoe Leviston, Jess Williamson \& Prof Marc Wilson 


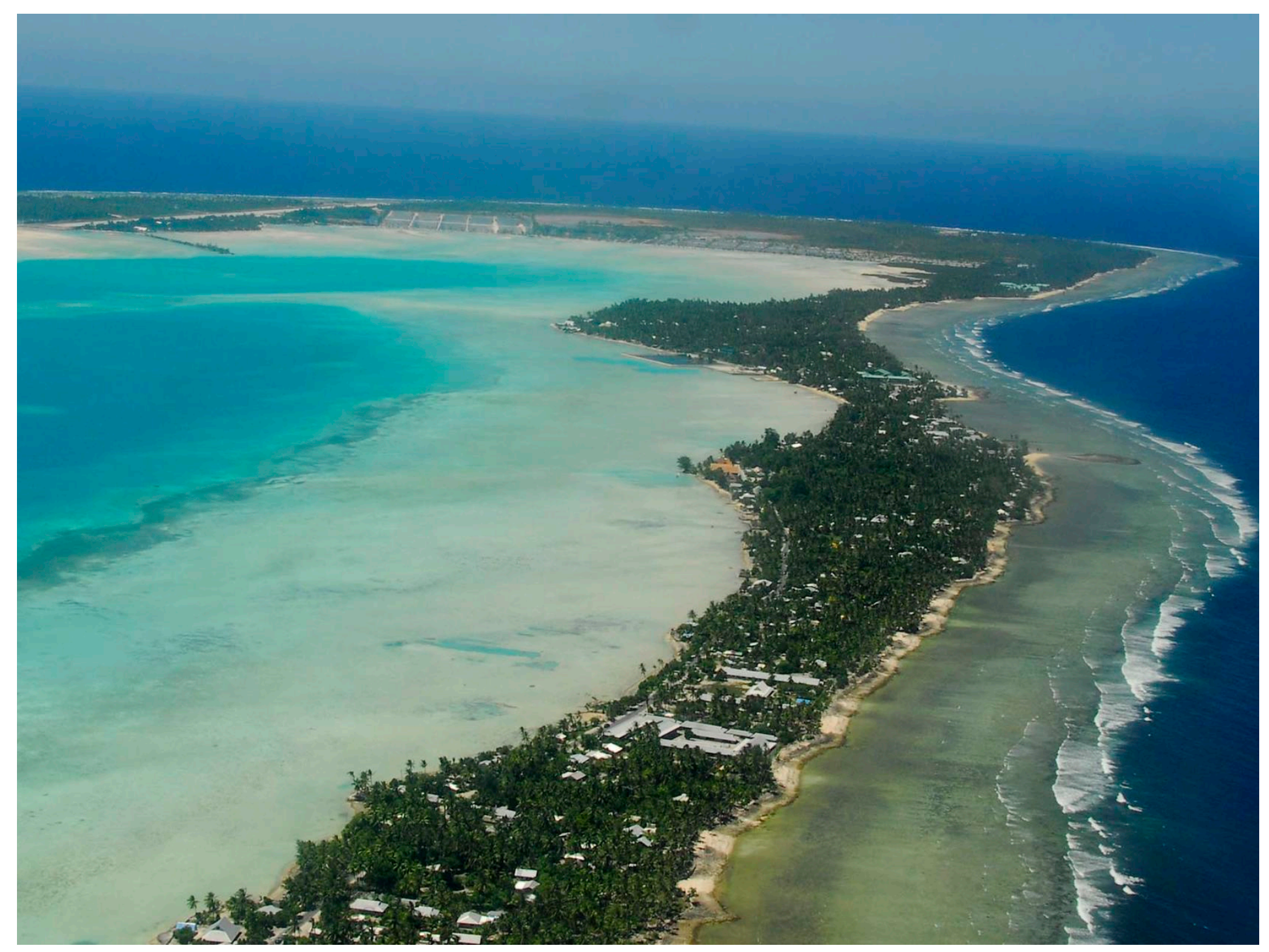

\section{SPSP}

\#SPSP2021 
Context: Australia and New Zealand
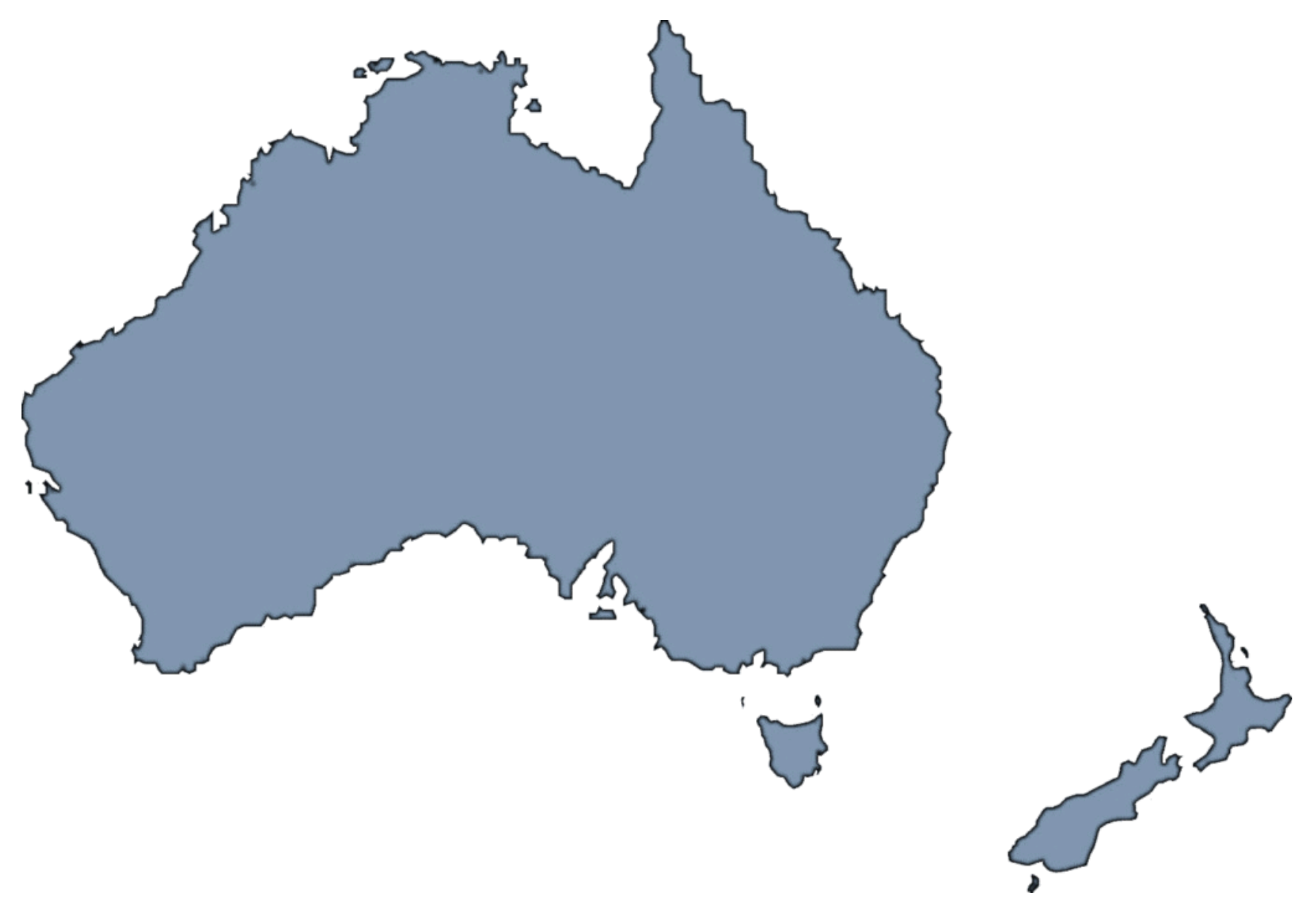

\section{SPSP}




\section{Support for climate-driven migration}

\begin{tabular}{|c|c|}
\hline New Zealand & \\
\hline $\begin{array}{l}\text { Sample } 1(\mathrm{~N}=2539) \\
\text { Accepting 'climate refugees', which are people who } \\
\text { have had to leave their country due to the effects of } \\
\text { climate change. }\end{array}$ & $\begin{array}{c}77 \% \text { Support } \\
M=5.25, S D=1.55\end{array}$ \\
\hline $\begin{array}{l}\text { Sample } 2(\mathrm{~N}=2293) \\
\text { New Zealand should accept refugees from low-lying } \\
\text { coastal nations that are displaced by climate change. }\end{array}$ & $\begin{array}{c}\text { 79\% Support } \\
M=5.34, S D=1.43\end{array}$ \\
\hline \multicolumn{2}{|l|}{ Australia ( $N=5106)$} \\
\hline $\begin{array}{l}\text { Accepting 'climate refugees', which are people who } \\
\text { have had to leave their country due to the effects of } \\
\text { climate change. }\end{array}$ & $\begin{array}{c}\text { 66\% Support } \\
M=5.05, S D=1.71\end{array}$ \\
\hline
\end{tabular}

\section{SPSP}




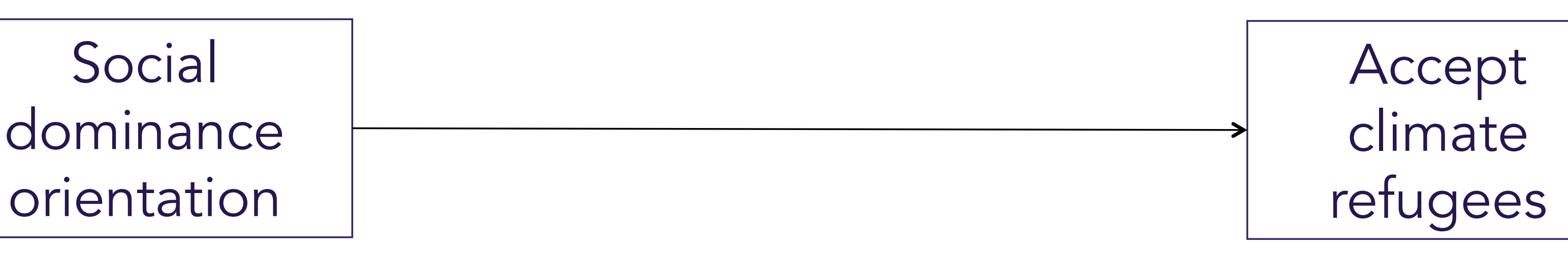

\section{SPSP}




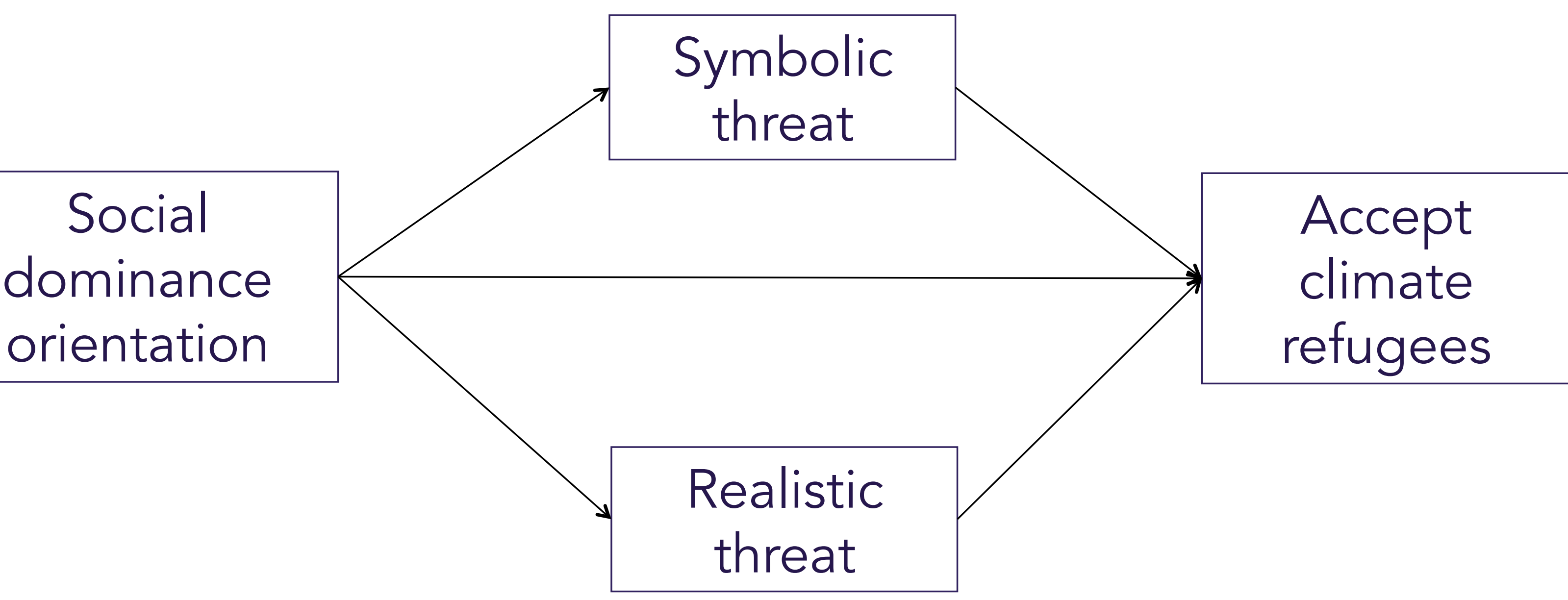

\section{SPSP}




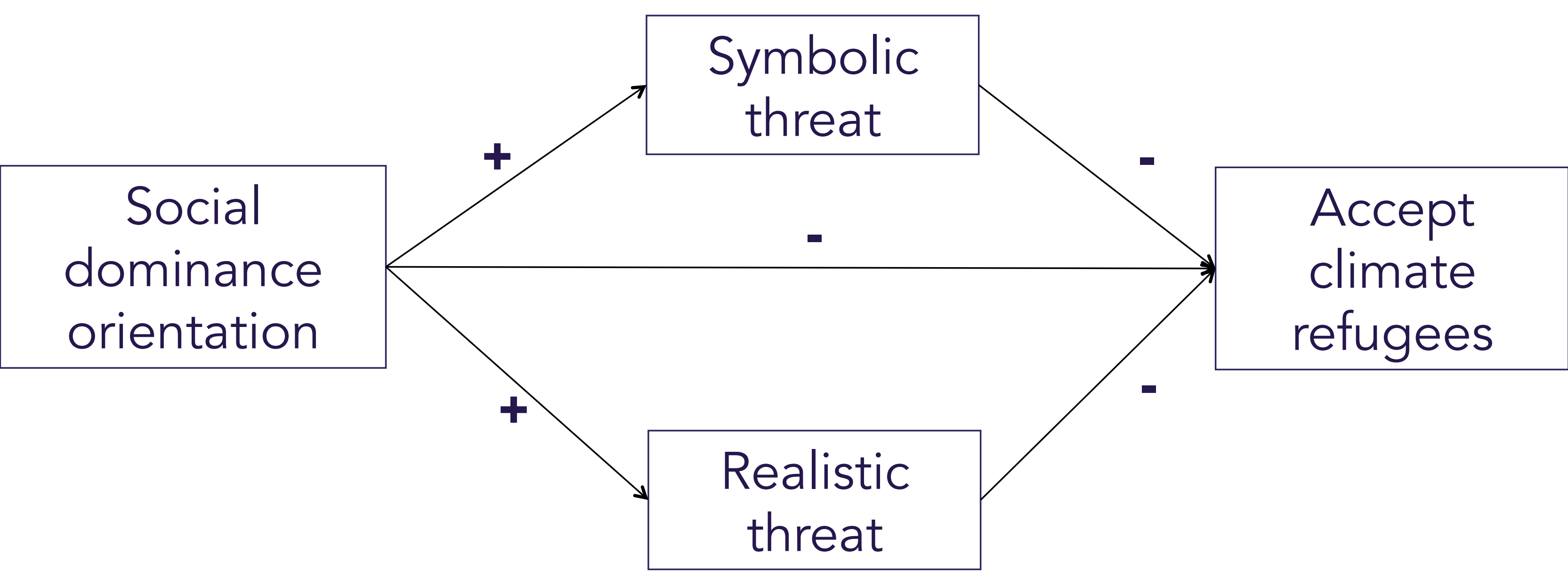

\section{SPSP}


Accepting 'climate refugees', which are people who have had to leave their country due to the effects of climate change.

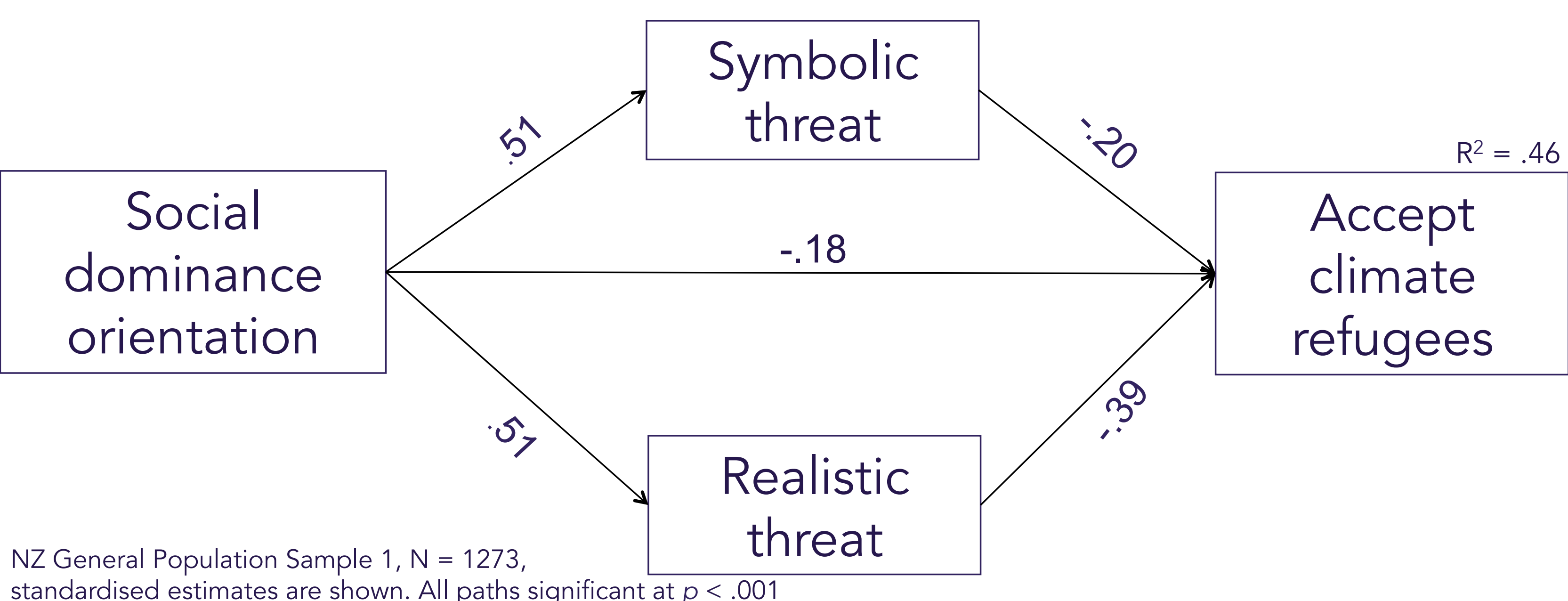


New Zealand should accept refugees from low-lying coastal nations that are displaced by climate change

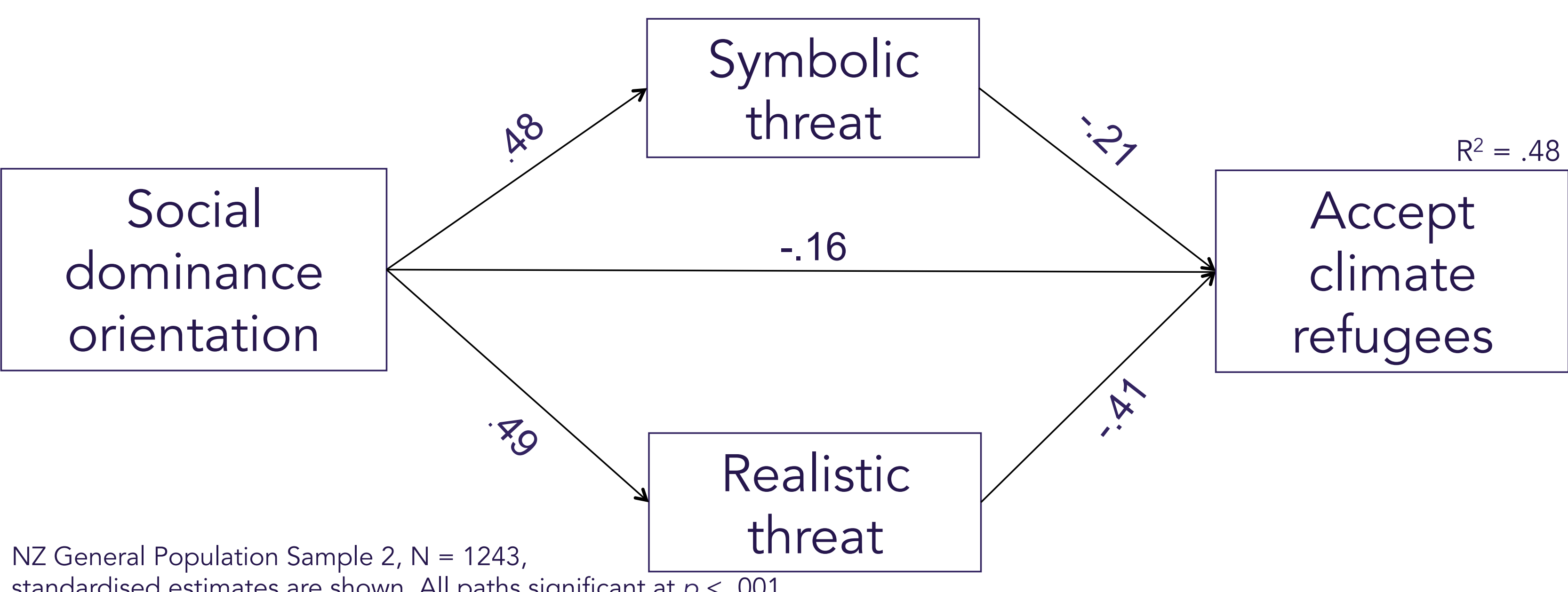




\section{Symbolic}

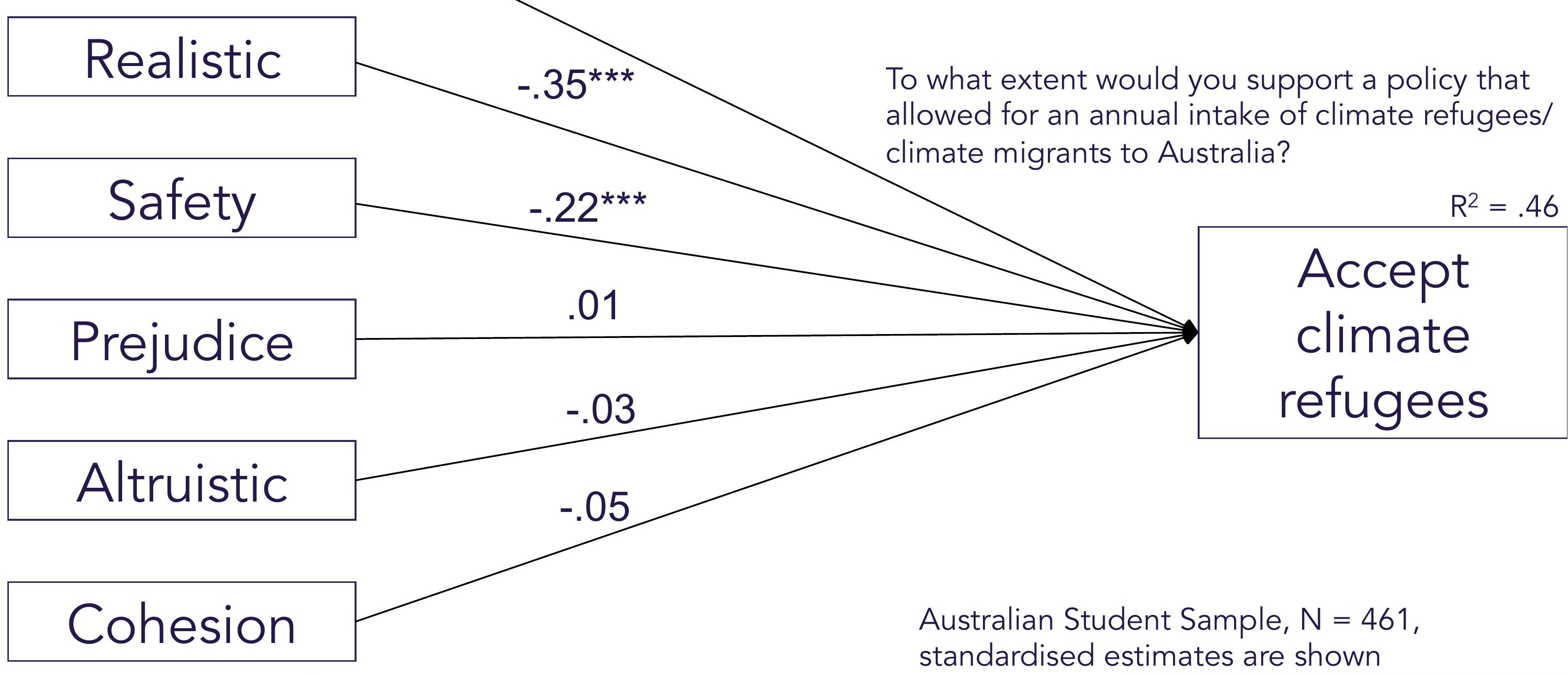

\section{SPSP}




\section{A note on terminology}

'Climate refugee' versus 'climate migrant' 


\section{Conclusions \& future directions}

- SDO and threat-based responses tell part of the story

- Perceived conflict over resources and values may undermine support for climate-driven migration

- Future research is needed to:

- Follow up experimental and longitudinal work needed to untangle potentially causal links

- Other factors likely shape support 


\section{Thank you}

Questions, comments, or possible collaborations?

Please email samantha.stanley@anu.edu.au

@SamanthaStanley 
Anmual Convention

SPSP 2021 GOES VIRTUAL

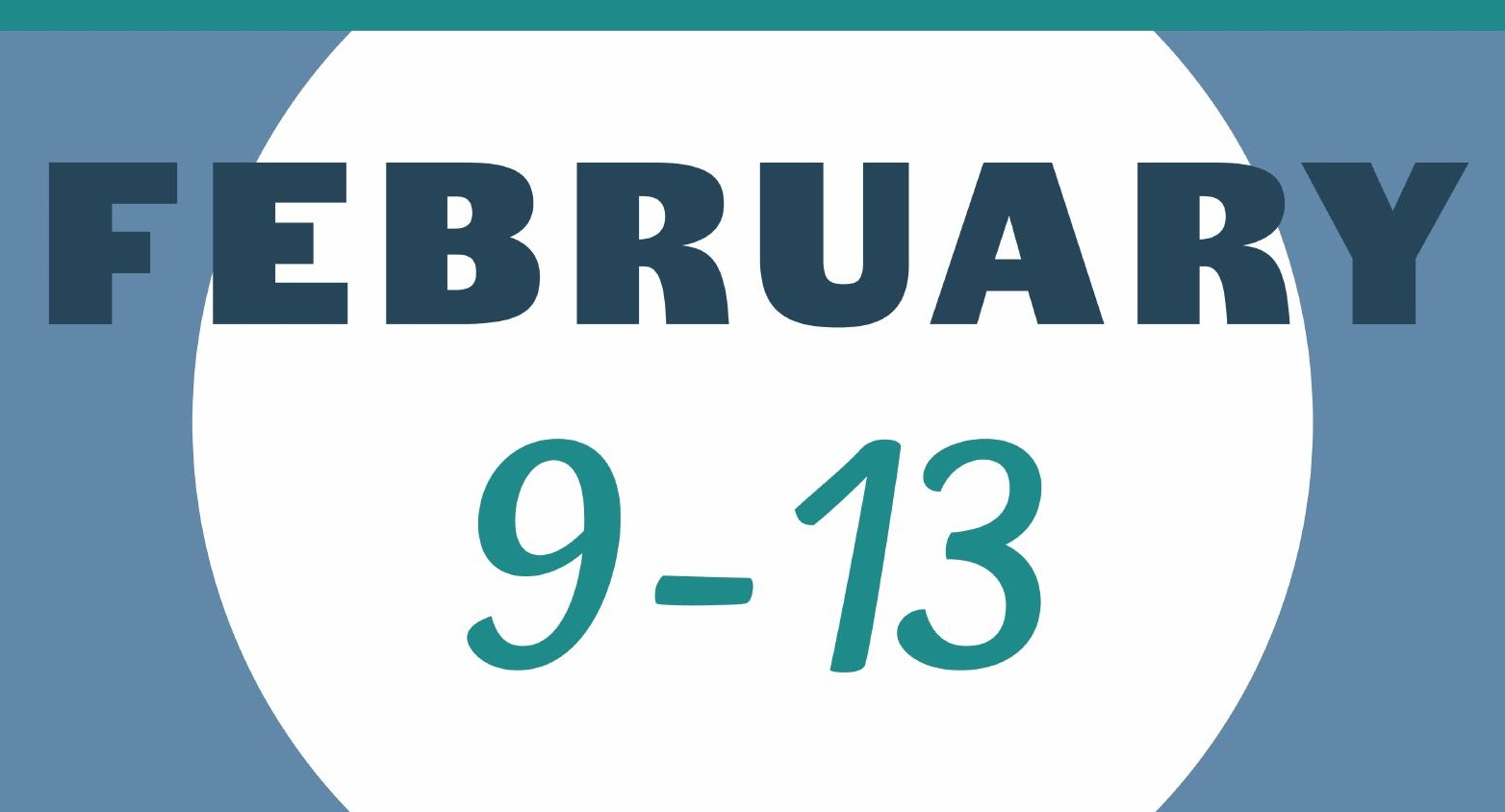

